\title{
The Informational Value of Job Search Data and the Dynamics of Search Behaviour: Evidence from Hungary
}

JOHN MICKLEWRIGHT and GYULA NAGY

Budapest Working Papers on the Labour Market BWP. 1999/1

March 1999 
Budapest Working Papers No.1999/1

Labour Research Department, Institute of Economics, Hungarian Academy of Sciences

Department of Human Resources, Budapest University of Economics

\section{The Informational Value of Job Search Data and the Dynamics of Search Behaviour: Evidence from Hungary}

Authors: John MICKLEWRIGHT, UNICEF International Child Develop-ment Centre. Address: Piazza Santissima Annunziata 12. 50122-Florence, Italy. Phone: 39-55 2345258; Fax: 39-55 244-817 (e-mail address: ciusco@uniceficdc.it)

Gyula NAGY, Department of Human Resources, Budapest University of Economics. Address: Fõvám tér 8. Budapest, H-1093 Hungary. Phone/fax: 36-1-217-1936 (e-mail address: gynagy@sunshine.bke.hu)

Published by the Institute of Economics, Hungarian Academy of Sciences.

Budapest, 1999.

With financial support from the Hungarian Economic Foundation and the Foundation for Job Creation 


\title{
THE INFORMATIONAL VALUE OF JOB SEARCH DATA AND THE DYNAMICS OF SEARCH BEHAVIOUR: EVIDENCE FROM HUNGARY*
}

\author{
JOHN MICKLEWRIGHT and GYULA NAGY
}

\begin{abstract}
Labour market analysis places much emphasis on the concept of search. But there is insufficient empirical information on (a) the relationship between reported search and job-finding and (b) how search behaviour changes over a spell without work. We investigate these issues using a sample constructed from Hungarian labour force survey panel data of the flow from jobs to the state of "joblessness". The results on job exits call into question aspects of the standard international classification of "unemployment" and "out of the labour force". Transitions during joblessness in and out of search and the various categories of non-search are found to be only modest.
\end{abstract}

\section{INTRODUCTION}

Both theoretical and empirical analyses of labour markets place much emphasis on the concept of job search. For example, the international standard for the measurement of unemployment based on the ILO/OECD criteria gives a central role to recorded search activity. But the body of evidence on actual search behaviour and its relationship with labour market flows is not as large as one might expect. In particular, there is relatively little evidence on two issues. First, is it the case that jobless persons recording search behaviour in surveys are much more likely to get jobs than those who do not? ${ }^{1}$ Second, how does search behaviour change over spells of joblessness? ${ }^{2}$

\footnotetext{
* The research for this paper was financed by EC PHARE-ACE grant P95-2081-R ("State Responses to Poverty and Unemployment in Hungary"). We thank the Hungarian Central Statistical Office, and especially Judit Lakatos, for providing us with labour force survey microdata and Stephen Jenkins for comments.

${ }^{1}$ One well-known paper that does address this issue is that by Flinn and Heckman (1983) who tested whether unemployment and out of the labour force represented behaviourally distinct states by estimating equations for movement from these two states into employment. Their analysis was restricted however to a very small and particular sample of US youths. See also Gönül (1992) and Osberg (1993). An important recent paper is Jones and Riddell (1998).

${ }^{2}$ Various authors have used cross-section data relating to the stock of those without work to estimate equations for the probability of search as a function of time since last job (e.g. Wadsworth, 1991). However, the stock provides a length-biased sample of spells of
} 
This paper provides evidence on these two issues using data from the labour force survey from Hungary. Although the results are restricted to this one country, the design of the Hungarian labour force survey shares important features with those from other OECD countries, allowing the analysis conducted here to be repeated elsewhere. In particular, the survey has a quarterly rotating panel design. This permits us to observe individuals moving out of jobs, their search behaviour while without work, and their subsequent re-employment (if any). Section 2 describes how we construct samples of data from the linked waves of the survey for 1993-97. We identify a sample of individuals (of both sexes) of working age who end jobs and enter the state of "joblessness". We then examine information on the search undertaken following job loss. We distinguish between "passive" and "active" search, which we expect to have different productivities in terms of job-finding, the former corresponding to visiting an employment office and the latter to other methods such as direct contact with employers and answering advertisements. And we distinguish the various categories in which a non-searcher can be - notably "discouragement", wanting work but not searching, and not wanting work - which may signify different degrees of attachment to the labour market.

Section 3 provides evidence on how the speed of return to work differs between those individuals recording search and those who do not. Does the knowledge that a workless person is classified as a searcher tell one much about his or her reemployment hazard? The evidence turns out to be mixed with some of it challenging standard classifications of attachment to the labour market. For example, the speed of return to work for men who report wanting work but not searching and not being discouraged - a group clearly designated as "out of the labour force" by the conventional ILO/OECD criteria - is equal or higher to that of men reporting use of the state employment office as their sole means of search - a group always classed as "unemployed".

Section 4 looks at search dynamics, focusing on how the individual probability of search changes over a spell of joblessness. Is there in fact much fall in the propensity to search as a spell of joblessness increases (an assumption often made to help justify the use of particular forms of base-line hazards in reduced form models of unemployment duration)? We find relatively little movement in and out of search, with, for example, moves from not wanting work into search being less frequent than from those directly into work. We find that giving up search, especially entering discouragement, is more likely where local unemployment is high but that increased time out of work is associated with a lower probability of ceasing search. Amongst those who have been without work for a year, most discouraged workers are discouraged from the outset of their spells of joblessness. Section 5 concludes.

\section{SPELLS OF ‘JOBLESSNESS’ IN LABOUR FORCE SURVEY PANEL DATA}

A behavioural measure of unemployment based on the standard ILO/OECD criteria

joblessness. Nor do these analyses show directly how search behaviour changes for individuals during a spell without work. 
of search and availability for work has been produced in Hungary since the start of 1992 when the necessary data began to be collected following the introduction of a household labour force survey (LFS). The LFS covers about 50,000 individuals, who are asked to participate in the survey for six consecutive quarters. Our investigation uses data from the 20 rounds of the survey that were conducted over 1993-97. Unemployment has been falling slowly throughout this period (having in fact reached its historical peak in the first quarter of 1993); the average unemployment rate for 1993 was 12 percent while by 1997 it had eased to 9 percent.

Our selection of a sample for analysis is designed to reduce some of the heterogeneity that exists among persons without work. In particular, we concentrate on those persons who are observed to cease a spell of work during their period of participation in the survey. Most discussion of search theory and most empirical analysis of unemployment duration concerns the behaviour of individuals who previously worked; for this reason we do not analyse search by those who have never worked or who have worked only a long time ago. And by selecting only from the flow into joblessness actually observed to occur in the survey (in the sense that an individual is observed in work in one quarter and not in the next), we ensure that search activity is monitored from the first quarter of job loss onwards. ${ }^{3}$

We then exclude men aged 56 and over and women aged 51 and over to avoid our results being affected by early retirement schemes for the unemployed available to persons who have received six months of unemployment insurance benefit and who are within three years of official retirement age (60 for men and 55 for women). We also discard those who leave work and directly enter receipt of child-care allowance or disability benefit and those who become full-time students. ${ }^{4}$ These are important allowances to make; about 15 percent of women who are observed in work in one quarter and not in work the next have moved from work to receipt of child-care allowance; and around 8 percent of spells of joblessness start with entry to receipt of disability benefit.

These selections result in a sample of 6,081 spells of joblessness of which one fifth are observed to end in re-employment during participation in the LFS panel (23 percent for men and 17 percent for women). It should be noted that a "spell", in our terminology, represents one or more quarters in which the individual is not working when interviewed; in practice it may not necessarily represent a continuous spell of

\footnotetext{
${ }^{3}$ Job loss may not of course necessarily occur in the first quarter of participation in the LFS; we include all individuals observed in a job at quarter $t$ and not in a job at quarter $t+1$, irrespective of whether $t$ is the first or a subsequent quarter. An individual will enter our sample more than once if he or she is observed to enter joblessness, return to work, and then enter joblessness again. Unfortunately, the data do not record the reason for job-loss (the information is collected only for those recording search). Given the rotating structure of the survey and our need to observe job-loss during panel participation (the date of job loss was not asked in the LFS of those without work until 1997), spells of joblessness observed in the selected sample are a maximum of four quarters long if completed and five quarters if incomplete.

${ }^{4}$ Where any of these states are entered from "joblessness", rather than directly from work, the jobless spell is treated in our econometric analysis as censored at the point where an individual moves to any of these states.
} 
joblessness since an individual may be briefly re-employed between quarterly interviews, a possibility that we do not observe and therefore ignore.

Table 1 shows the search behaviour in all observed quarters following job loss. (Persons receiving maternity or child-care allowance are excluded.) Search refers to the four weeks prior to the interview and individuals are asked to report up to three methods if any search has been used. (The restriction of the period to the four previous weeks is unfortunate since there may be unobserved changes in search behaviour between interviews outside of the four week window.)

We define "passive" search as visiting the state employment office. Of course, in many cases this may in fact be an positive step towards finding new work. But since receipt of unemployment benefit (whether insurance or assistance benefit) requires regular registration at employment offices, it is possible that reported search that is a visit to the employment office is only a passive by-product of collecting benefits. ${ }^{5}$ "Active" search is taken to be any other search method (although some require more effort on the part of the individual than do others): use of a private employment agency, placing or checking advertisements, direct application to employers, use of personal connections (e.g. friends and relatives). The last three rows in Table 1 distinguish between persons undertaking passive or active search alone and those reporting both.

The group of jobless persons not undertaking any search is divided into five groups:

People who report that they do not want a job.

Those reporting that they expect recall to their previous job and that this is the reason they have not searched.

So-called "discouraged" workers: people reporting that they want work but that they have not searched for it because of some reason related to the labour market - for example, a belief that there is no job available in their occupation, or due to a high level of unemployment in their locality. The status of discouraged workers in OECD countries, including their degree of attachment to the labour market, has been the source of considerable debate (Hussmans et al, 1990, OECD, 1987, 1995).

Persons who say they want work but who are not classified as "discouraged".

Those engaged in "casual work" - the respondent reports having done some work in the previous week despite having no job. Such persons are usually classified as employed in official publications using labour force survey data but we want to see if casual work is - in the same way as search should be - a step towards finding a

\footnotetext{
${ }^{5}$ It is important to note that information on registration of unemployment and on job search are covered by different parts of the LFS questionnaire, and it is not the case that a person registered as unemployed is recorded by definition as having undertaken search for work at the employment office (or vice versa). For example, about 30 percent of those reporting only passive search are not registered as unemployed. (Overall, about a third of women and a half of men are registered as unemployed in the first quarter of job loss.)
} 
proper job. (No questions in the LFS relating to search are asked of casual workers. $)^{6}$

The most obvious feature of Table 1 is perhaps the stability in the frequencies of each category over the different quarters. The relative importance of most categories changes little, although this may disguise many individual transitions, a subject we return to in Section 4. It should also be noted that there will be sorting in the sample as durations lengthen and some persons return to work. ${ }^{7}$

From the first quarter following job loss onwards, a large proportion of persons of both sexes who do not record search. This applies to as many as 58 percent of women and to 43 percent of men. Figure 1 shows the percentage that do report passive and/or active search in each quarter. The search frequency appears to fall with the fourth and fifth quarter but the smaller sample sizes at this point should be noted. (The 95 percent confidence interval around the search propensity in the fifth quarter is $+/-6$ percent points for both genders.)

For both sexes, "not wanting" a job is the most frequent category of non-search in the first quarter, applying to nearly a third of all women and 1 in 7 men, but when one takes into account the discouraged the majority of men not searching do report wanting work. Discouragement is perhaps surprisingly high at this point in the jobless spell; it is more important for men, and the number of discouraged workers grows somewhat in importance over time, becoming the modal group of nonsearchers at the fourth quarter. Expecting recall accounts for only 1 in 20 men immediately following job loss, and even less women, and declines in importance over time.

Turning to the reported type of search, the most frequent search category for both sexes is the combination of passive and active, something true in every quarter. ${ }^{8}$ Its importance rises for men in the second quarter of joblessness to account for more than a third of the observed months and then stays at this level. Overall, men seem clearly to be more attached to the labour market than women: they are more likely to search, to use active methods if searching, and to be discouraged or at least reporting that they want a job if not undertaking search.

The significance of the degree of search activity revealed in Table 1 depends on the link between search and job-finding. The next section investigates this issue before turning to the transitions in and out of search at the individual level.

\footnotetext{
${ }^{6}$ In common with many other countries, Hungarian statistics treat all casual workers as "employed". This results from use of a very low threshold of weekly hours of work to define employment (just one hour).

7 Table 1 shows the number of observations of joblessness declining very rapidly as the number of quarters lengthens. In part this is due to re-employment - jobless spells ending in work - but the main reason is censoring; the jobless spell may not begin until late in the period of participation in the LFS.

${ }^{8}$ A prominent feature of the search data not shown in the table is the large fall in "passive only" search over 1993-97. The ratio of any active to passive only search in the first quarter more than doubles, to 4:1 for women and 6:1 for men in 1997.
} 


\section{SEARCH STATUS AND THE PROBABILITY OF RETURN TO WORK}

If the ILO/OECD definition of unemployment is an informative classification of labour market behaviour, recently employed persons in a spell of worklessness who are recorded as undertaking search can be expected to return to work more quickly than those not searching. ${ }^{9}$ We may also expect active search to be more productive than search that is restricted to merely visiting the state employment office. And if the standard criteria of labour market status do hold information about labour market attachment, among those not searching the "discouraged" may return to work faster than others. Finally, those who merely report wanting a job should return to work much more slowly than those conducting search.

Table 2 shows the transition rates revealed in the data from the different categories of search and non-search in quarter $r_{t}$ to jobs in quarter ${ }_{t+1}$, pooling all quarters of observation. ("Jobs" include self-employment as well as employment.) Overall, about 1 in 6 men and 1 in 7 women leave joblessness for employment each quarter, a low figure reflecting in part the low turnover of the unemployed pool in the transition economies of Central Europe (Boeri, 1994).

The clearest results are found for women. All three categories of search have exit rates to jobs that are two to three times above that for those who say that they do not want a job. Search is certainly associated with a much faster return to work compared to not wanting a job, a category which has the lowest re-employment rate of all - although it is worth noting that, at 7 percent, it is not negligible. Those wanting a job and those who are discouraged have a virtually identical exit probability that comes between those searching and those not wanting a job - as one would expect. In other words, the fact that a person is searching does reveal more about their job prospects than one can tell from the knowledge that someone merely wants a job. On the other hand, the additional information that someone wanting a job is discouraged is not informative about their hazard. Finally, those expecting recall have the highest transition rate of all - the expectation is in this sense not misplaced.

The results are less clear-cut for men and differ in a number of important respects from those for women. Those searchers reporting just passive search have a re-employment rate that is insignificantly different from that of men who say that they do not want a job at all, who have an exit rate as high as 12 percent. In contrast with women, this category of search has no more informational value for a man's job prospects than merely wanting a job but not searching. And men both passively and actively searching - the modal group among men - have a transition rate that is only one standard error higher than that of those just wanting a job. Yet another result that differs from that for the women is that the discouraged workers have the same exit rate as those not wanting work at all. Two results that do correspond to those for the women are that expecting recall is again very important and that there is no evidence that casual work represents a special "way-station" along the road to re-employment;

\footnotetext{
${ }^{9}$ This does not in fact go without saying. The recorded search activity is by definition in the past while the job finding is in the future. But if search status changes only slowly over a spell of joblessness then job finding should occur more frequently among those who have searched in the recent past.
} 
the exit rate here for both sexes is effectively the same to that for those not wanting work.

The different types of search and the various states of non-search may be associated with characteristics that are also correlated with the re-employment probability. To see if these results change when we control for the observed characteristics of individuals in the different groups, we estimate a discrete-time duration model of the job-exit hazard from spells of joblessness. Spells ending in states other than employment are treated as censored at the point of exit. The hazard is specified as a logit function of a set of dummies for search and desire for work with those individuals not wanting a job forming the base category. Controls are entered for age, education, time since job loss (measured in quarters), the local unemployment rate, residence in Budapest, marital status and whether the respondent has a young child, the number of employed people in the household, and for the receipt of unemployment insurance and unemployment assistance benefit. ${ }^{10}$ The dummies indicating search and desire for work can vary over the spell as behaviour and attitudes to work change (some of the controls also vary with duration). Parameters are estimated following the procedure outlined in Jenkins (1995).

Table 3 gives results obtained on the variables of interest, separately for men and women. The first specification for each gender excludes the control variables, so as to have a benchmark for their impact. (These results merely reproduce in a parametric framework the sample transition rates calculated non-parametrically in Table 2.) The lack of any significant difference between discouragement and the base of not wanting work is shown for men. Passive search has only a small and weakly significant impact for men. Testing revealed that the hypothesis that all three search categories have the same hazard for women cannot be rejected, implying that in their case there is no practical distinction in terms of success in finding jobs between active and passive search.

The results change relatively little when the control variables are added to the model. The absolute size of the coefficients diminishes somewhat but the basic picture remains the same. Among women, discouragement is no longer significant at the 5 percent level and the same is true of wanting work for the men.

The standard ILO/OECD criteria for classification of labour market status treats merely wanting work, expecting recall, or discouragement as "out of the labour market". And search is treated as a necessary condition for "unemployment" (and a sufficient condition in conjunction with reporting availability for work). The results in Tables 2 and 3 suggest that attachment to the labour market among persons recently leaving jobs is far from ideally measured by the ILO/OECD criteria. The case of recall is the most obvious and may come as no surprise. But the finding that "wanting work" - a much more quantitatively important category than recall - has a notably stronger (men) or equal (women) association with re-employment to that of "discouragement" is more surprising. This casts doubt on the attention that is often

\footnotetext{
10 The local unemployment rate is the rate of registered unemployment in the relevant quarter in the employment office area in which the individual resides. There are 180 such areas.
} 
paid to the discouraged in discussion of the boundaries of the definition of unemployment. ${ }^{11}$ In the case of men, these boundaries are also challenged by the result that "wanting work" is associated with an as high or higher speed of reemployment as that of passive search alone and a very similar transition rate to that of the modal group of jobless men, those both passively and actively searching. Among men, even those who report not wanting a job at all return to work at a speed that is little lower than that of several other groups, including some searchers.

\section{THE DYNAMICS OF SEARCH BEHAVIOUR}

Does search behaviour change much over a spell of joblessness? Table 1 showed that the overall distribution of observed jobless months among the different categories of search and non-search changed little across the quarters that make up our jobless spells. But this hides any transitions at the individual level. Besides the intrinsic interest in this issue, the implications of the results in the last section may be less if transitions in and out of search are very important. Someone merely wanting work this quarter may have obtained a job by next quarter because they started searching. And someone who searches this quarter whom we observe failing to get a job by the following quarter may simply have given up search.

Table 4 shows the quarter $r_{t}$ to quarter ${ }_{t+1}$ transition matrix, pooling all quarters of observation, between the three categories of search taken together and the nonsearch categories. The matrix also includes persons exiting from joblessness to employment and these transitions rates, shown earlier in Table 1, provide a comparator for the movements between other cells.

There is little movement out of search. Conditional on there being any move, by far and away the biggest transition is to jobs, and the (unconditional) rate to all other states is only 5 percent for men and 7 percent for women. Among men these moves are largely to discouragement or wanting work while for women the move to not wanting a job is the modal one. The bottom line in the table for each sex shows that only about 8 percent of the persons searching at $t+1$ were not doing so at $t$. As with search exits, most of this movement into search comes from the states of wanting work or discouragement - much of the flow to and from search is therefore from these "marginally attached" states. And the transition rates from either of these states into search are broadly similar to those into work.

The greatest stability in the transition matrix is for not wanting work and for casual work. The transition rate into search from not wanting work is only 5 percent for men and 2 percent for women, well less than the exit rates from these states directly into jobs.

As noted earlier, the status of discouragement has received considerable attention in the literature on the measurement of labour market status. The word "discourage" suggests a dynamic process - people first try to find work and then give

11 In published Hungarian LFS statistics, the "discouraged" are the only group of nonsearchers that are separately identified. 
up in the light of their experience of the process. But is this what typically happens? Table 1 shows that the overall proportion of discouraged persons changes relatively little as joblessness lengthens but there is clearly more movement at the individual level. Table 4 shows that about one fifth of the discouraged at $q_{t+1}$ have entered since the last quarter, and (something not shown in the table) about half come from search and about half from other states. Table 5 shows more directly the numbers of discouraged workers with previous search. At each observed spell length, it gives the proportions of discouraged workers who have been (a) always discouraged since entry into joblessness, and (b) who have previously searched at any time in the jobless spell. The size of the stock of discouragement in the first quarter shown in Table 1 and the relatively low rates of transition into discouragement from search shown in Table 4 result in the figures for the later quarters in Table 5. For example, the majority of persons who are classified as discouraged workers in their fourth quarter of joblessness have been in that state from the outset of job loss and only one quarter have recorded any prior search. The process of discouragement that is often discussed when justifying, for example, a base-line hazard in a reduced-form model of unemployment duration - searchers giving up looking for work - does not correspond well to the bulk of "discouragement" measured in these data.

Table 4 pools all transitions across the quarters. Any changes in the transition rate over the spell out of search are reflected in the survivor functions given in Figure 2. A spell of joblessness ending in an exit to a job is treated as censored in the estimation of these survivor functions, hence their values at any point are higher than would be implied by Table 3 in which jobs are treated as an exit state. Figure 2 therefore shows estimates of the probability of survival in search conditional on remaining jobless. Women give up search somewhat more quickly than men, especially active search. But the probability of searching continuously until the fifth quarter of joblessness is not much less than 0.9 even for women, and 0.8 for continuous active search.

Some search, however, clearly does cease as the time out of work lengthens. Does the period out of work itself and the strength of the local labour market have much impact on the search probability? Much discussion of the concept of search in models of unemployment assumes so. To investigate the issue we estimate discrete-time models of the duration of search (restricting analysis to spells in which the first quarter following job loss was spent searching). Results are given in Table 6. Models are estimated both for the duration of any type of search and for duration of active search (with or without passive search). We first estimate by binary logit models of the probability of exit to any other state, i.e. to all states of non-search and to all states other than active search respectively. We then go on to estimate competing risk models by multinomial logit of the separate hazards of exit to not wanting work, to wanting work and to discouragement. Spells of search finishing in an exit to jobs are treated as censored in all models. In the competing risk models, the exits to states other than those on which we focus (i.e. exits to expected recall or casual work, and, in the case of the model of duration of active search, to passive only search) are lumped together as an "other exits" group, for which we do not report the estimated coefficients). 
Is it the case that the local unemployment rate has an impact too on the state initially occupied following jobloss (conditional on not moving straight from the old job to a new one)? To address this question we also report in Table 6 the results of a binary logit model of the probability of not conducting any type of search in the first quarter of joblessness, and a multinomial model of the probabilities that the first quarter was spent in the three non-search states of not wanting work, wanting a job, and discouragement - with any search taken as the base state. These models of the state in the first quarter are reported as line (c) in the table, with the models of exit from any search and from active search as lines (a) and (b) respectively.

All the models are estimated pooling men and women. Table 6 shows the results of coefficients on the local unemployment rate and on dummies for time (in quarters) since job loss intended to pick up duration dependence in the search probability. The third and fourth quarter dummies are grouped to preserve sample size. $^{12}$ (The models of the state in the first quarter - line (c) - obviously contain no quarter dummies.) A similar set of controls is included to that used in the models in Table 2 but we report only the estimated coefficient on a female dummy, which is given in the final column.

The first line of results shows that giving up any form of search is indeed somewhat more likely where unemployment is higher. A difference in the local unemployment rate of 12 percent points has the same impact as the difference between being a man and a woman, shown in the last column; both raise the search exit hazard by about a third of its previous value. The result is consistent with that in line (c); the probability of not searching in the first quarter is affected by the local unemployment rate by broadly the same amount. However quitting active search, line (b), does not seem affected by local unemployment.

The quarter dummies produce some surprising results. Ceteris paribus, the probability of giving up search falls quite sharply with increasing duration, the coefficient being especially well determined for quits from active search. It is of course possible that unobserved heterogeneity is driving this result - those who are not very serious in their search intentions give up earlier, leaving behind a residual group surviving to longer durations who are more resilient in their search efforts.

The bottom part of the table shows how these results vary across different exits or states of non-search. It is clear that entering discouragement or being discouraged in the first quarter of joblessness is strongly associated with higher local unemployment but that the other states are not. The probability of moving into discouragement, whether direct from work or after a period of search, is therefore indeed more likely where unemployment is higher, as one would expect from the way that discouragement is defined. But we also see that exits to all three states are less likely as spells lengthen, although the disaggregation in this case results in

\footnotetext{
12 The duration dummies show the impact of duration at time $t$ on the transition between $t$ and $t+1$. Since the observed spells of joblessness in our data are a maximum of five quarters, the last quarter dummy that can be entered in the model is for the fourth quarter (measuring the effect of duration of search on the transitions between fourth and fifth quarters).
} 
coefficients that are not well determined. There is no support here for a view of discouragement becoming more likely as a spell without work proceeds.

\section{CONCLUSIONS}

The importance of search in labour market measurement and analysis implies that actual data on reported search by jobless persons need to be investigated from a variety of angles. Our emphasis has been on dynamic aspects of search data. First, we have shown how search information recorded in labour force survey data during spells of joblessness experienced by recently employed persons is - or is not related to actual job finding. Second, we have investigated how search behaviour changes - or does not - over a spell of joblessness. Our main results include the following findings, which have implications for standard classifications of "unemployment" and "out of the labour force" and for the way that search analysts may think of the search process:

Men reporting search through public employment offices and at least one other method (the modal group in the sample) had an exit rate to jobs that was insignificantly different from that of men merely reporting that they wanted a job and who did not search. This calls into doubt the standard international classification that labels the former group as "unemployed" and the latter as "out of the labour force". The same is true of the finding of no significant difference between the transition rates to jobs of those searching through employment offices alone and those saying that they did not want to work at all.

Among women there was a clear ranking in terms of speed of return to work: searchers, followed by the discouraged and those wanting work, and then those not wanting jobs. As with the men, controlling for a variety of observed individual characteristics had little impact on the results.

The equivalence between female re-employment rates of the discouraged and those merely wanting work implies the emphasis often placed in discussion of labour market status on the former group is mis-placed. This conclusion is reinforced by the results for men that show the discouraged returning to work at the same speed as those not wanting work at all.

Transitions in and out of search during spells of joblessness occur at only a low level, much lower than the transitions from either search or from not wanting work to re-employment (themselves low in the Hungarian data we use).

Women were found to be somewhat more likely than men to give-up search having started it, and more likely to move to not wanting work at all if they did give up. But the biggest gender difference was in the probability of starting search following job loss, with women much less likely than men to search.

The probability of giving up search, and especially search by any method other than use of a public employment office, appears to fall with the length of time out of work, and not to rise as is often assumed in much discussion of the search process. 
However, the strength of the local labour market has a significant impact on not searching following job loss and on becoming discouraged if search is begun.

Our results refer only to Hungary. However, recent evidence from Canada found by Jones and Riddell (1998) on the relationship between, on the one hand, different categories of search and non-search and, on the other, actual job-finding calls into question the standard international classification of labour market status in a similar way to our results. The survey design exploited by Jones and Riddell is similar to that of the Hungarian LFS, a quarterly rotating panel, that we have been able to exploit here. This common design of labour force surveys in much of the rest of the OECD means that the informational value of search data and patterns of search behaviour during spells without work can be studied elsewhere. 


\section{REFERENCES}

Boeri, T, 1994, "Transitional' Unemployment", Economics of Transition, 2(1):1-26.

Flinn C and Heckman J, 1983, "Are Unemployment and Out of the Labour Force Behaviourally Distinct States?", Journal of Labor Economics, 1(1): 28-42.

Jones S and Riddell C, 1995, "The Measurement of Labor Force Dynamics with Longitudinal Data: the Labour Market Activity Survey Filter", Journal of Labor Economics, 13: 351-85.

Jones S and Riddell C, 1998, "The Measurement of Unemployment: An Empirical Approach", McMaster University, mimeo (forthcoming Econometrica).

Gönül, F, 1992, "New Evidence on Whether Unemployment and Out of the Labor Force Represent Behaviourally Distinct States", Journal of Human Resources, 27: 329-61.

Hussmans, R, Mehran, F, and Verma, V, 1990, Surveys of Economically Active Populations, Employment, Unemployment and Underemployment: An ILO Manual on Concepts and Measures, International Labour Office, Geneva.

Jenkins, S, 1995, "Easy Estimation Methods for Discrete-Time Duration Models", Oxford Bulletin of Economics and Statistics, 57: 129-38.

OECD, 1987, "On the Margin of the Labour Force: An Analysis of Discouraged

Workers and other Non-Participants", Employment Outlook, OECD, Paris

OECD, 1995, "Supplementary Measures of Labour Market Slack", Employment Outlook, OECD, Paris

Osberg L, 1993, "Fishing in Different Ponds: Job-Search Strategies and Job-Finding Success in Canada in the Early 1990s", Journal of Labor Economics, 11(2): 348386.

Wadsworth J, 1991, "Unemployment Benefits and Search Effort in the UK Labour Market", Economica, 58: 17-34. 


\section{TABLES}

\section{Table 1: Job Search by Duration of Joblessness}

a) Men

„Search method:"

Does not want a job

Wants a job

Expects recall

Discouraged

Passive search only

Active search only

Active + passive search

Casual work

Total

No. of observations

\begin{tabular}{rrrrr}
\hline \multicolumn{5}{c}{ Duration of joblessness, quarter } \\
\hline \multicolumn{1}{c}{$r$} & \multicolumn{1}{c}{3} & \multicolumn{1}{c}{4} & \multicolumn{1}{c}{5} \\
\hline 14.1 & 12.7 & 12.2 & 12.1 & 15.1 \\
9.9 & 8.7 & 8.4 & 8.7 & 7.2 \\
5.0 & 3.2 & 2.3 & 1.2 & 1.5 \\
10.8 & 11.5 & 12.1 & 15.6 & 13.6 \\
12.1 & 12.2 & 11.8 & 10.3 & 9.8 \\
15.1 & 12.6 & 13.3 & 11.3 & 12.1 \\
29.5 & 34.7 & 35.5 & 35.2 & 36.2 \\
3.6 & 4.4 & 4.5 & 5.7 & 4.5 \\
100.0 & 100.0 & 100.0 & 100.0 & 100.0 \\
$3,55_{\varsigma}^{\prime}$ & 2,081 & $1,18<$ & 611 & 265
\end{tabular}

b) Women

„Search method:”

Does not want a job

Wants a job

Expects recall

Discouraged

Passive search only

Active search only

Active + passive search

Casual work

Total

No. of observations

\begin{tabular}{rrrrr}
\hline \multicolumn{5}{c}{ Duration of joblessness, quarter } \\
\hline \multicolumn{1}{c}{2} & \multicolumn{1}{c}{3} & \multicolumn{1}{c}{4} & \multicolumn{1}{c}{5} \\
\hline 30.4 & 29.9 & 30.7 & 31.2 & 41.0 \\
13.1 & 12.5 & 12.2 & 12.9 & 10.7 \\
3.0 & 2.5 & 1.4 & 1.9 & 2.0 \\
7.6 & 7.4 & 7.2 & 9.5 & 7.8 \\
10.4 & 11.2 & 10.4 & 10.2 & 9.8 \\
9.8 & 7.0 & 6.0 & 3.8 & 5.9 \\
22.2 & 25.3 & 26.5 & 24.8 & 19.5 \\
3.7 & 4.3 & 5.7 & 5.7 & 3.4 \\
100.0 & 100.0 & 100.0 & 100.0 & 100.0 \\
2,52 & $1,51^{-}$ & 874 & 420 & 205
\end{tabular}


Table 2: Quarterly Transition Rates from Search and Non-Search to Re-

\section{Employment}

„Status at $t: ”$

\begin{tabular}{|c|c|c|c|}
\hline \multicolumn{2}{|c|}{ Men } & \multicolumn{2}{|c|}{ Women } \\
\hline rate & st. error & rate & st. error \\
\hline
\end{tabular}

Does not want a job

0.120

$(0.014) \quad 0.069$

$(0.032)$

Wants a job

0.156

$(0.017) \quad 0.109$

$(0.047)$

Expects recall

0.409

(0.035) $\quad 0.347$

$(0.083)$

Discouraged

0.112

(0.013) $\quad 0.103$

$(0.057)$

0.135

$(0.014) \quad 0.161$

(0.047)

Active search only

0.226

$(0.016) \quad 0.203$

$(0.055)$

0.165

(0.009) $\quad 0.161$

$(0.031)$

Casual work

0.095

(0.021)

0.073

(0.079)

All

0.164

(0.005)

0.129

$(0.016)$

Note: Transition rates are calculated by pooling all $\mathrm{q}_{\mathrm{t}}$ to $\mathrm{q}_{\mathrm{t}+1}$ transitions and excluding spells ending in movement to child care allowance or disability benefit.

Table 3: Re-Employment Hazards in Discrete-Time Model of Duration of Joblessness (logit functional form)

\begin{tabular}{|c|c|c|c|c|c|c|c|c|}
\hline \multirow[t]{3}{*}{ „Search method:” } & \multicolumn{4}{|c|}{ Men } & \multicolumn{4}{|c|}{ Women } \\
\hline & \multicolumn{2}{|c|}{ No controls } & \multicolumn{2}{|c|}{ With controls } & \multicolumn{2}{|c|}{ No controls } & \multicolumn{2}{|c|}{ With controls } \\
\hline & coeff. & $\mathrm{t}$ & coeff. & $\mathrm{t}$ & coeff. & $\mathrm{t}$ & coeff. & $\mathrm{t}$ \\
\hline Wants a job & 0.41 & 2.3 & 0.32 & 1.8 & 0.55 & 2.7 & 0.44 & 2.2 \\
\hline Expects recall & 1.73 & 9.5 & 1.65 & 8.6 & 2.09 & 8.8 & 1.92 & 7.6 \\
\hline Discouraged & 0.08 & 0.4 & 0.11 & 0.6 & 0.58 & 2.5 & 0.46 & 1.9 \\
\hline Passive search only & 0.27 & 1.6 & 0.27 & 1.5 & 1.08 & 5.8 & 0.91 & 4.5 \\
\hline Active search only & 0.82 & 5.3 & 0.72 & 4.6 & 1.28 & 6.6 & 1.03 & 5.1 \\
\hline Active + passive search & 0.51 & 3.6 & 0.50 & 3.4 & 1.07 & 6.8 & 0.91 & 5.3 \\
\hline Casual work & -0.13 & -0.5 & -0.15 & -0.6 & 0.18 & 0.6 & -0.03 & -0.1 \\
\hline Constant & -2.55 & -20.3 & -3.12 & -24.8 & -3.16 & -24.8 & -2.24 & -8.3 \\
\hline log-likelihood & \multicolumn{2}{|c|}{-2459.7} & \multicolumn{2}{|c|}{-2397.1} & \multicolumn{2}{|c|}{-1434.0} & \multicolumn{2}{|c|}{-1386.3} \\
\hline No. of spells & \multicolumn{4}{|c|}{3,552} & \multicolumn{4}{|c|}{2,529} \\
\hline
\end{tabular}

Note: Controls are included for education (4 dummies), age (4 dummies), receipt of UI or of UA (2 dummies), the local area unemployment rate, Budapest, marital status and presence of a small child (2 dummies), the number of employed people in the household, and number of quarters since job loss (3 dummies). All search method variables and all control variables (other than education and age) may vary with duration. Spells ending in transition to any state other than work are treated as censored. 
Table 4: Transitions between Search and Non-Search

a) Men

Does not want a job

\begin{tabular}{rrrrrrrr}
\hline \multicolumn{7}{c}{ Status at $\mathrm{q}(\mathrm{t}+1)$} \\
\hline $\begin{array}{c}\text { Does } \\
\text { not } \\
\text { want }\end{array}$ & $\begin{array}{c}\text { Wants } \\
\text { a job }\end{array}$ & $\begin{array}{c}\text { Expects } \\
\text { recall }\end{array}$ & $\begin{array}{c}\text { Discou- } \\
\text { raged }\end{array}$ & Search & $\begin{array}{c}\text { Casual } \\
\text { work }\end{array}$ & Job & Total \\
\hline 79.5 & 1.1 & 0.5 & 1.8 & 4.8 & 0.4 & 12.0 & 100.0 \\
2.0 & 62.3 & 1.1 & 4.3 & 14.4 & 0.2 & 15.6 & 100.0 \\
2.0 & 3.0 & 40.4 & 3.5 & 9.1 & 1.0 & 40.9 & 100.0 \\
2.1 & 2.6 & 0.7 & 69.6 & 12.8 & 1.0 & 11.2 & 100.0 \\
1.0 & 1.4 & 0.3 & 2.0 & 77.4 & 0.6 & 17.3 & 100.0 \\
1.5 & 1.0 & 0.5 & 3.5 & 3.5 & 81.1 & 9.5 & 100.0
\end{tabular}

Wants a job

Expects recall

Discouraged

Search

Casual work

$\%$ in state at $\mathrm{q}(\mathrm{t}+1)$

also in state at $\mathrm{q}(\mathrm{t})$

$\begin{array}{llllll}88.6 & 79.5 & 78.4 & 80.0 & 92.2 & 85.8\end{array}$

b) Women

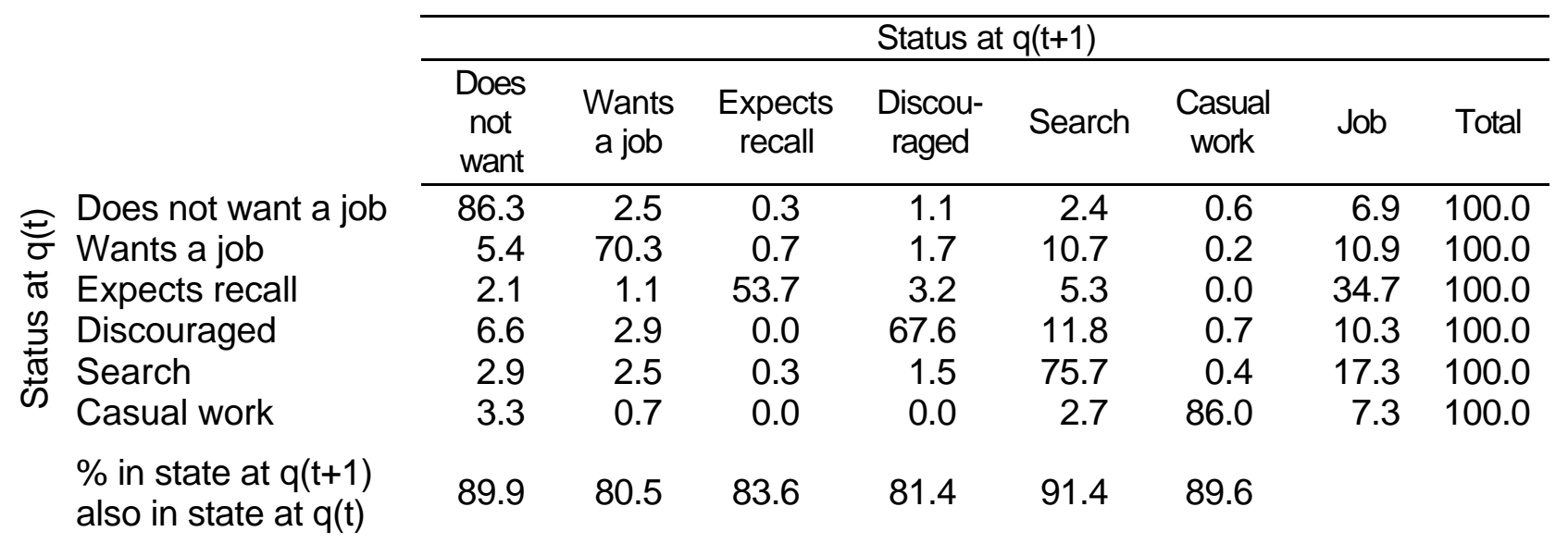

Note: Transition rates are calculated by pooling all $\mathrm{q}_{\mathrm{t}}$ to $\mathrm{q}_{\mathrm{t}+1}$ transitions and excluding spells ending in movement to child care allowance or disability benefit. 
Table 5: Prior State of Discouraged Workers

\begin{tabular}{lccccc}
\cline { 2 - 6 } & \multicolumn{5}{c}{ Duration of joblessness, quarter } \\
\cline { 2 - 6 } & 1 & 2 & 3 & 4 & 5 \\
\cline { 2 - 6 } & $\%$ & $\%$ & $\%$ & $\%$ & $\%$ \\
Always dicouraged & 100 & 78.7 & 64.2 & 56.3 & 34.6 \\
Any prior search & 0 & 12.0 & 19.6 & 27.4 & 42.3 \\
No. of dicouraged workers & 575 & 350 & 204 & 135 & 52
\end{tabular}

Table 6: Hazards in Discrete-Time Models of Duration of Search and of Search Status in First Quarter

\begin{tabular}{cccc}
\hline \multicolumn{4}{c}{ Coefficient (t-statistic) } \\
\hline $\begin{array}{c}\text { Local } \\
\begin{array}{c}\text { unemployment } \\
\text { rate }\end{array}\end{array}$ & $\begin{array}{c}2 \text { quarters } \\
\text { since job loss }\end{array}$ & $\begin{array}{c}3 \text { quarters since } \\
\text { job loss }\end{array}$ & Female \\
\hline
\end{tabular}

1. Binary logit results:
a) Exit from any search
0.033
(2.2) $\quad-0.29$
(2.0)
$-0.56$
(3.1) $\quad-0.41$
b) Exit from active search
$0.008 \quad(0.9)$
$-0.41 \quad(4.6)$
$-0.76$
(6.8)
$-0.14$
c) No search in first quarter
$0.043(6.7)$
$0.075(14.2)$

2. Multinomial logit results:

a) Exit from any search to:

$\begin{array}{lllllllll}\text { Does not want a job } & -0.005 & (0.2) & -0.07 & (0.3) & -0.46 & (1.6) & 0.99 & (4.8) \\ \text { Wants a job } & -0.053 & (1.7) & -0.26 & (0.9) & -0.58 & (1.7) & 0.47 & (1.9) \\ \text { Discouraged } & 0.122 & (4.3) & -0.57 & (1.8) & -0.39 & (1.2) & -0.39 & (1.4)\end{array}$

b) Exit from active search to:

$\begin{array}{lrlllllll}\text { Does not want a job } & 0.017 & (0.6) & -0.11 & (0.4) & -0.52 & (1.4) & 1.00 & (4.0) \\ \text { Wants a job } & -0.043 & (1.2) & -0.41 & (1.2) & -0.76 & (1.7) & 0.80 & (2.8) \\ \text { Discouraged } & 0.118 & (4.0) & -0.45 & (1.3) & -0.55 & (1.4) & -0.11 & (0.4)\end{array}$

c) No search in first quarter:

$\begin{array}{llllllr}\text { Does not want a job } & 0.014 & (1.8) & - & - & 0.98 & (16.2) \\ \text { Wants a job } & 0.002(0.2) & - & - & 0.56 & (6.9) \\ \text { Discouraged } & 0.139(12.7) & - & - & 0.04 & (0.4)\end{array}$

Note: Controls included but not reported in the table are education ( 4 dummies), age (4 dummies), Budapest, marital status and presence of a small child (2 dummies), and the number of employed people in the household. Spells ending in transition to work are treated as censored in both the search duration models. The local unemployment rate is the rate of registered unemployment in the relevant quarter in the employment office area (of which there are 180) in which the individual resides. 


\section{FIGURES}

Figure 1: Search Frequency by Quarter of Joblessness

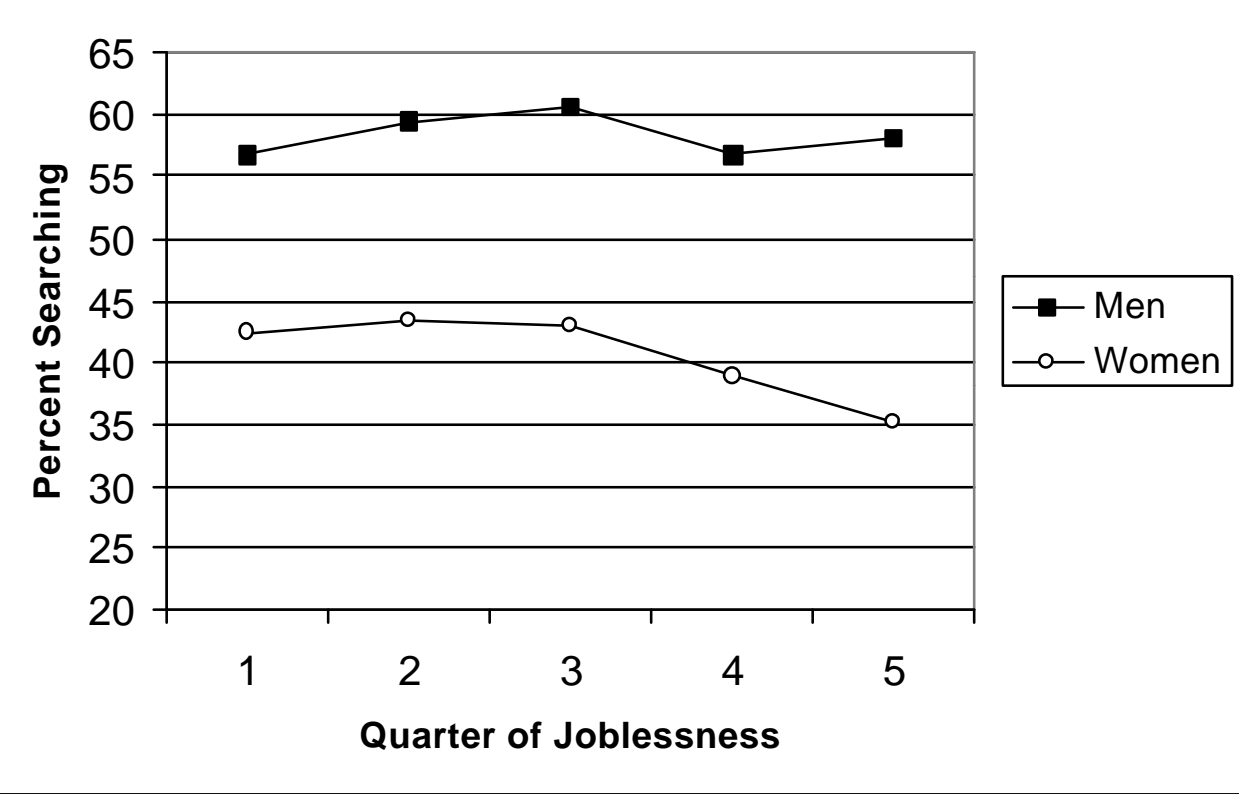


Figure 2: Survival in Search and in Active Search

a) any search

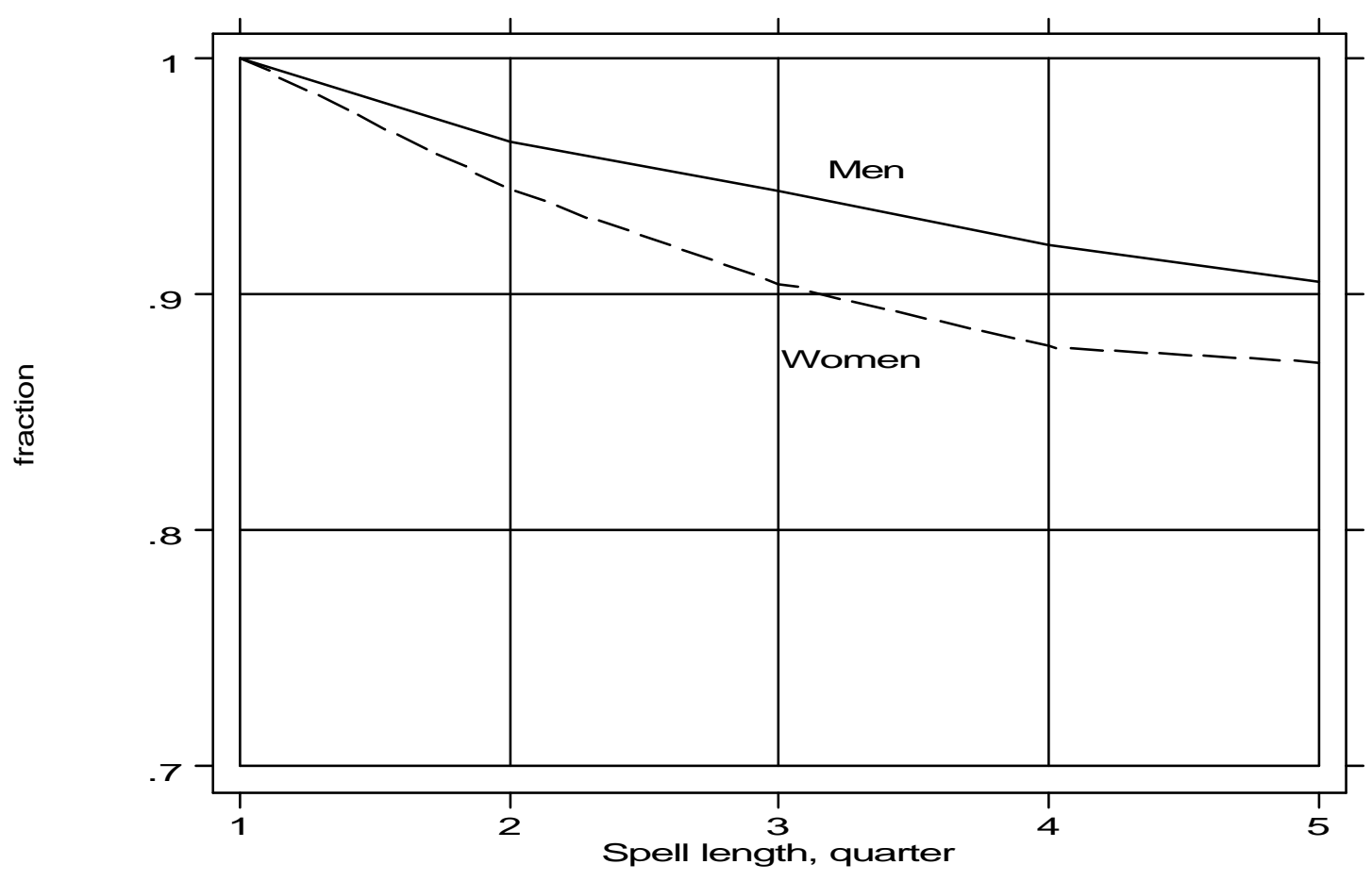

b) active search

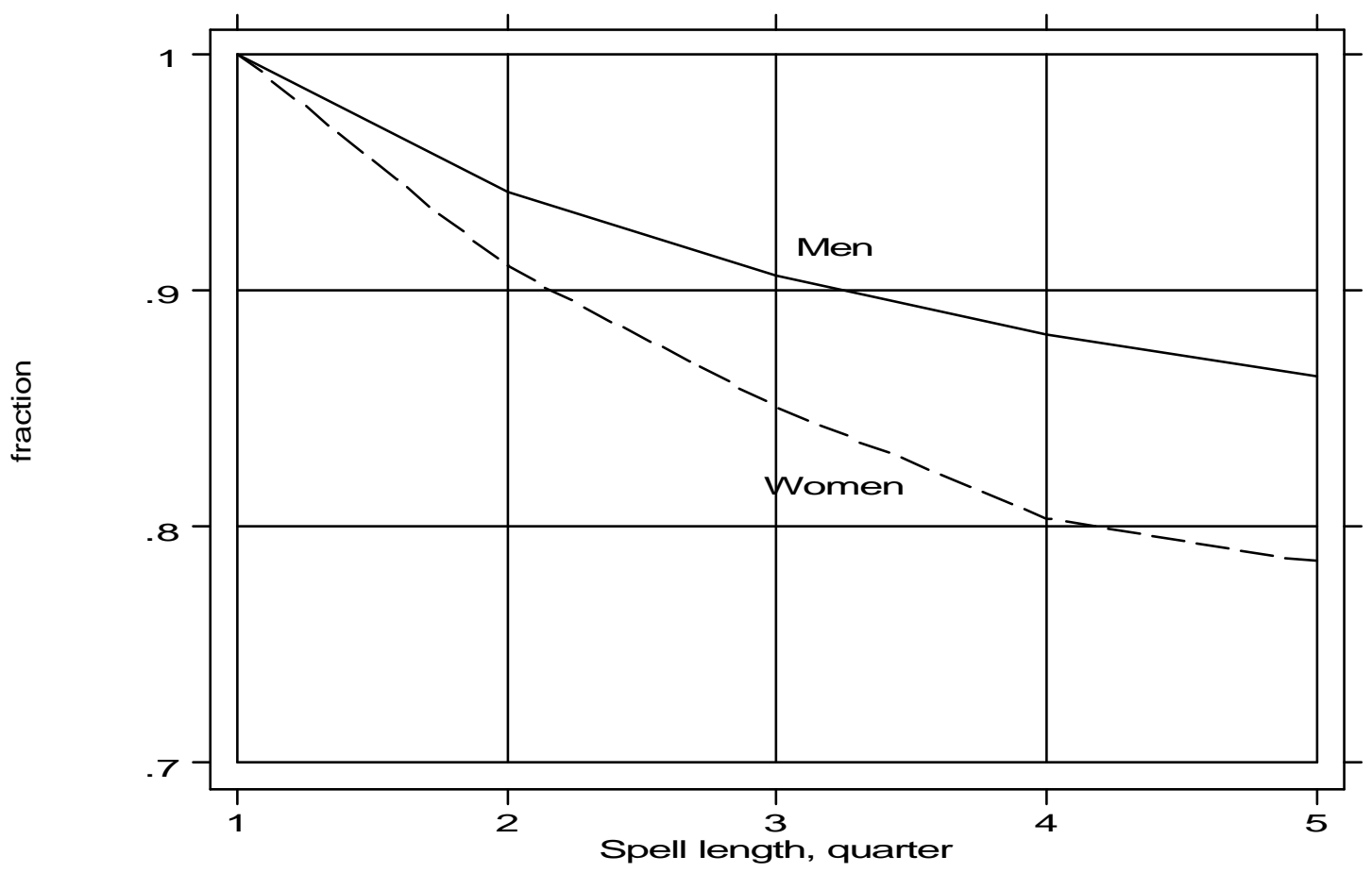

Note: Spells ending in transition to work are treated as censored. 